\title{
Outcome and prognostic factors of children with Philadelphia chromosome-positive acute lymphoblastic leukemia treated with imatinib followed by allogeneic hematopoietic cell transplantation in first remission
}

\author{
Juae Shin, Na Yeong Lee, Seongkoo Kim, Jae Wook Lee, Pil-Sang Jang, Nack-Gyun Chung, Bin Cho \\ Department of Pediatrics, The Catholic University of Korea, Seoul, Korea
}

p-ISSN 2287-979X / e-ISSN 2288-0011
https://doi.org/10.5045/br.2019.54.1.45
Blood Res 2019;54:45-51.

Received on September 15, 2018

Revised on October 6, 2018

Accepted on October 10, 2018

\author{
Correspondence to \\ Bin Cho, M.D., Ph.D. \\ Nack-Gyun Chung, M.D., Ph.D. \\ Department of Pediatrics, Seoul Saint \\ Mary's Hospital, The Catholic University \\ of Korea, Seocho-gu, Banpo-daero 222, \\ Seoul 06591, Korea \\ E-mail: B.C., chobinkr@catholic.ac.kr \\ N.G.C., cngped@catholic.ac.kr \\ (C) 2019 Korean Society of Hematology
}

\begin{abstract}
Background
Philadelphia chromosome-positive acute lymphoblastic leukemia $(\mathrm{Ph}+\mathrm{ALL})$ is a subset of ALL with poor prognosis. Here, we analyzed the outcomes and prognostic factors of children with $\mathrm{Ph}+\mathrm{ALL}$ who received imatinib and chemotherapy followed by allogeneic hematopoietic cell transplantation (HCT) in first complete remission (CR).

\section{Methods}

Thirty-one Ph+ ALL patients (female 10) diagnosed from January 2005 to December 2016 were included in the study. All patients were treated with imatinib and chemotherapy before $\mathrm{HCT}$. Bone marrow (BM) evaluations included real-time quantitative polymerase chain reaction (RQ-PCR) study of the BCR-ABL1 fusion transcript. All patients received HCT with total body irradiation (TBI)-based conditioning at a median of 6.4 (range, 4.247.1) months from diagnosis.
\end{abstract}

\section{Results}

Compared to values at diagnosis, the median decrement of RQ-PCR value post-consolidation, and prior to HCT was $-3.7 \mathrm{Log}$ and $-4.8 \mathrm{Log}$, respectively. The 5-year event-free survival (EFS) and overall survival of the patients were $64.5 \pm 9.4 \%$ (20/31) and $75.0 \pm 8.3 \%$ $(23 / 31)$ respectively. Events included relapse $(\mathrm{N}=5)$ and death in $\mathrm{CR}$ post- $\mathrm{HCT}(\mathrm{N}=6)$. The 5-year incidence of molecular relapse was $30.9 \pm 9.1 \%$ (9/31). An RQ-PCR decrement of at least -4 Log post-consolidation significantly predicted lower incidence of molecular relapse: $7.7 \pm 7.7 \%$ for $\geq-4 \log$ decrement, $50.0 \pm 13.8 \%$ for $<-4$ Log decrement $(P=0.027)$.

\section{Conclusion}

Decrement in RQ-PCR for the BCR-ABL1 transcript that was determined after consolidation was the only significant prognostic factor for incidence of molecular relapse. In the post-induction TKI initiation setting, steadfast imatinib treatment during consolidation may allow for optimum post-HCT outcomes.

Key Words Acute lymphoblastic leukemia, Philadelphia chromosome, Children, RQ-PCR

\section{INTRODUCTION}

Philadelphia chromosome-positive acute lymphoblastic leukemia $(\mathrm{Ph}+\mathrm{ALL})$ comprises about $3-5 \%$ of pediatric ALL and is known to have inferior outcomes compared to other ALL subtypes [1]. Prior to the incorporation of targeted therapy, in the form of tyrosine kinase inhibitors (TKIs), such as imatinib, into the treatment scheme, the long-term event-free survival (EFS) reported from key studies was approximately $30 \%$, with allogeneic hematopoietic cell transplant (HCT) recipients having superior outcomes compared with patients treated with chemotherapy only [2, 3]. Subsequently, the introduction of imatinib therapy con- 
currently with conventional chemotherapy significantly improved the survival of pediatric $\mathrm{Ph}+\mathrm{ALL}$ patients, as has been shown in several prospective studies [4-7]. Furthermore, an update of the initial Children's Oncology Group (COG) trial showed that patients who completed treatment with imatinib and chemotherapy only had an EFS comparable to those who subsequently underwent allogeneic HCT [8].

Our institution's strategy for the Ph+ ALL subgroup is to classify the patients as very high risk, administer imatinib with chemotherapy, and undertake allogeneic HCT in first complete remission (CR) from a matched sibling (MSD) or unrelated donor (MUD) [9]. Regarding imatinib and chemotherapy combination, studies from adult $\mathrm{Ph}+\mathrm{ALL}$ patients show that the decrement in minimal residual disease (MRD) as measured by real-time quantitative polymerase chain reaction (RQ-PCR) for the $B C R-A B L 1$ fusion transcript significantly influences outcomes $[10,11]$. Prognostic factor studies in pediatric $\mathrm{Ph}+\mathrm{ALL}$ patients who were treated in the TKI era are few, with one study reporting that patients with additional cytogenetic abnormalities have lower survival [8].

Here, our aim was to show the outcomes of Ph+ ALL patients who were administered imatinib combined with chemotherapy, followed by allogeneic HCT in first CR at our institution, and to determine factors with prognostic significance. As well as clinical and transplant-related factors, we studied whether sequential RQ-PCR measurement of the fusion transcript identified patients with poor outcomes.

\section{MATERIALS AND METHODS}

\section{Patient group}

$\mathrm{Ph}+\mathrm{ALL}$ patients diagnosed at the Department of Pediatrics, The Catholic University of Korea from January 2005 to December 2016, and treated with imatinib and chemotherapy, followed by allogeneic HCT in first CR were included in the study ( $\mathrm{N}=31$ ) (Table 1). Patients who completed treatment without transplant, or who received HCT in second CR or later were excluded. The median age and white blood cell (WBC) count at diagnosis were 12.7 years and $72,200 / \mu \mathrm{L}$, respectively. None of the patients had central nervous system (CNS) involvement at diagnosis. Twenty-four (77\%) of the patients had additional cytogenetic abnormalities besides the $\mathrm{Ph}$ chromosome according to Giemsa band karyotyping (Supplementary Table 1).

\section{Chemotherapy}

Remission induction and subsequent chemotherapy until transplant, was based on an institutional regimen [9]. Consolidation chemotherapy duration in our regimen was 8 weeks (Supplementary Table 2). Patients diagnosed until December 2008 were administered dexamethasone during all phases of steroid treatment (CMCP-ALL2005); subsequent patients received prednisolone (CMCP-ALL2009). Notably, the initial 7 patients here were administered 1-5 courses of anthracycline (idarubicin or daunorubicin) and high dose cytarabine combination after remission induction instead of our ALL post-induction treatment. All but 4 patients started imatinib after initial remission induction at a dose of $340 \mathrm{mg} / \mathrm{m}^{2} /$ day and were treated with the TKI continuously until conditioning for HCT; the remaining 4 patients were administered imatinib during remission induction. Five of the patients (16\%) failed to achieve CR after initial remission induction and achieved CR after second induction chemotherapy or consolidation. Routine TKI therapy post-transplant was not done; only patients who showed an increase in the $B C R-A B L 1 \mathrm{RQ}-\mathrm{PCR}$ transcript post-HCT re-started TKI therapy.

\section{$B C R-A B L 1$ evaluation}

$\mathrm{Ph}+\mathrm{ALL}$ was diagnosed by reverse-transcription polymerase chain reaction (RT-PCR) for the fusion transcript and bone marrow (BM) karyotyping. Leukemic burden was assessed by RQ-PCR measurement of the $B C R-A B L 1$ transcript at diagnosis, post-consolidation, just prior to HCT, and at $1,3,6,9$, and 12 months post-HCT with a BM specimen, and utilizing a quantification kit for each fusion transcript (BioSewoom Inc., Seoul, Korea). The relative expression level of the gene was calculated using the $2^{-\Delta \Delta \mathrm{Ct}}$ method by normalizing to the geometrical mean of $A B L 1$ as a stable reference gene and presenting it relative to the control.

\section{Study outcomes}

The first objective of our study was to determine the 5-year EFS, overall survival (OS), incidence of relapse and non-relapse mortality (NRM) post-transplant of our study group. We also calculated incidence of molecular relapse; while considering an increase in $B C R-A B L 1 \mathrm{RQ}-\mathrm{PCR}$ value post-transplant which required the re-initiation of TKI therapy, regardless of BM morphology, an event. Isolated extra-

Table 1. Patient characteristics

\begin{tabular}{|c|c|}
\hline & $N=31(\%)$ \\
\hline \multicolumn{2}{|l|}{ Gender } \\
\hline Male/female & $21(68) / 10(32)$ \\
\hline Age at diagnosis, median (range) & $12.7 \mathrm{yr}\left(6.5^{-17.7)}\right.$ \\
\hline Initial WBC count, median (range) & $72,200 / \mu \mathrm{L}(1,290-687,230)$ \\
\hline \multicolumn{2}{|c|}{$\mathrm{NCl}$ risk group } \\
\hline Standard/high & $3(10) / 28(90)$ \\
\hline \multicolumn{2}{|l|}{ Transcript subtype } \\
\hline e1a2/e1a3/b2a2/b3a2 & $21(68) / 1(3) / 6(19) / 3(10)$ \\
\hline \multicolumn{2}{|l|}{ Additional cytogenetic abn. } \\
\hline Yes/no & $24(77) / 7(23)$ \\
\hline \multicolumn{2}{|l|}{ Treatment regimen } \\
\hline CMCPL-ALL2005/-ALL2009 & $12(39) / 19(61)$ \\
\hline \multicolumn{2}{|l|}{ Steroid response ${ }^{\text {a) }}$} \\
\hline Good/poor & $21(68) / 9(29)$ \\
\hline
\end{tabular}


medullary relapse was also considered an event in the incidence of molecular relapse calculation. EFS was defined as the time from HCT to last follow-up in CR, or the first event, which included relapse or death from any cause; OS was defined as the time from HCT to last follow-up, or death from any cause.

Additionally, we attempted to define clinical and chemotherapy-related (age and WBC count at diagnosis, presence of additional cytogenetic abnormalities, steroid response, chemotherapy protocol), transplant-related [donor type, human leukocyte antigen (HLA) disparity, infused TNC and CD34+ cell dose, acute and chronic graft-versus-host disease (GVHD)], and RQ-PCR-based MRD factors [values at diagnosis, log decrement post-induction, post-consolidation, just prior to HCT,and achievement of molecular remission (RQ-PCR of ' 0 ')] which significantly influenced either the EFS or incidence of molecular relapse.

\section{Statistical analysis}

Continuous variables were dichotomized according to respective median values in order to analyze their impact on outcomes. Disparity in RQ-PCR decrement according to the type of chemotherapy was calculated using the MannWhitney test. Survival rates were calculated according to Kaplan-Meier method and comparisons were done with the Log-rank test. The impact of acute and chronic GVHD on EFS were analyzed using GVHD as a time dependent covariate in the Cox proportional hazard regression. Incidence of relapse, molecular relapse, NRM, and acute and chronic GVHD were calculated by the cumulative incidence function with consideration of the competing risks, and comparisons

\begin{tabular}{lc}
\hline Table 2. Transplant characteristics. & \\
\hline & $\mathrm{N}=31(\%)$ \\
\hline Time to transplant, median (range) & $6.4 \mathrm{mo}(4.2-47.1)$ \\
Donor type & \\
Matched related/unrelated & $8(26) / 23(74)$ \\
Cell source & $4(13) / 24(77) / 3(10)$ \\
BM/PBSC/CB & \\
HLA disparity & $20(65) / 11(35)$ \\
Match/mismatch & $12(39)$ \\
Conditioning & $17(55)$ \\
TBI-Cy \pm ATG & $2(6)$ \\
TBI-Ara-Cy \pm ATG & \\
TBI-Flu-Ara & $28(91)$ \\
GVHD prophylaxis & $1(3)$ \\
Cyclosporine + MTX & $2(6)$ \\
Cyclosporine + MMF & \\
Tacrolimus + MMF &
\end{tabular}

${ }^{a)}$ HLA matching based on high resolution typing of HLA-A, $-B,-C$, -DR alleles.

Abbreviations: Ara, cytarabine; ATG, anti-thymocyte globulin; BM, bone marrow; $\mathrm{CB}$, cord blood; $\mathrm{Cy}$, cyclophosphamide; Flu, fludarabine; GVHD, graft-versus-host disease; HLA, human leukocyte antigen; MMF, mycophenolate mofetil; MTX, methotrexate; PBSC, peripheral blood stem cells; TBI, total body irradiation. were done with Gray's test. Patient follow-up was done until July 19th, 2018. $P$-values $<0.05$ were considered significant.

\section{RESULTS}

\section{Transplantation}

Patients received HCT in first CR at a median of 6.4 months from diagnosis (range, 4.2-47.1 mo). The majority of patients underwent unrelated donor HCT (Table 2). All patients underwent total body irradiation (TBI)-based myeloablative conditioning. Median infused cell doses were as follows: total nucleated cell (TNC) $13.6 \times 10^{8} / \mathrm{kg}(0.5-23.2)$, mononuclear cell $10.0 \times 10^{8} / \mathrm{kg}(0.3-19.8)$, CD34+ cell $5.0 \times$ $10^{6} / \mathrm{kg}(0.1-29.3)$, CD3+ cell $40.3 \times 10^{7} / \mathrm{kg}(0.6-133.0)$.

Cumulative incidence of acute GVHD grade II-IV and chronic GVHD were $74.2 \pm 8.2 \%(23 / 31)$ and $48.4 \pm 9.7 \%$ (15/31) respectively, with $13.0 \pm 6.2 \%$ (4/31) incidence for at least grade III acute GVHD, and $32.4 \pm 8.6 \%$ (10/31) incidence for at least moderate chronic GVHD. Severe chronic GVHD was diagnosed in 5 patients (16.1\%).

\section{Fusion transcript RQ-PCR}

The median RQ-PCR value for the $B C R-A B L 1$ transcript at diagnosis was 1.09 (range, 0.21-9.13) (Table 3), and the median decrement of the RQ-PCR value post-consolidation was -3.72 Log. The difference in post-consolidation RQ-PCR decrement according to the type of consolidation chemotherapy (that is, between patients who received institutional CMCP-ALL regimen and the seven patients who received anthracycline and high dose cytarabine) was not significant $(P=0.210)$. Twelve $(39 \%)$ and $15(48 \%)$ patients achieved

Table 3. Changes in RQ-PCR value for BCR-ABL1 fusion transcript.

\begin{tabular}{|c|c|}
\hline & $\mathrm{N}=31(\%)$ \\
\hline Median value at diagnosis (range) & $1.09(0.21-9.13)$ \\
\hline \multicolumn{2}{|l|}{ Post-induction } \\
\hline Median RQ-PCR decrement (range) $)^{a)}$ & $-1.22(-5.40-0.07)$ \\
\hline \multicolumn{2}{|l|}{ Post-consolidation } \\
\hline Median RQ-PCR decrement (range) & $-3.72(-5.55-1.51)$ \\
\hline \multicolumn{2}{|l|}{ Decrement } \\
\hline$\geq-4 \log /<-4 \log$ & $13(42) / 17(55)$ \\
\hline \multicolumn{2}{|l|}{ Molecular remission ${ }^{\text {b) }}$} \\
\hline Yes/no & $12(39) / 18(58)$ \\
\hline \multicolumn{2}{|l|}{ Prior to $\mathrm{HCT}$} \\
\hline Median RQ-decrement (range) & $-4.81(-5.55-0.42)$ \\
\hline \multicolumn{2}{|l|}{ Decrement } \\
\hline$\geq-4 \log /<-4 \log$ & $17(55) / 14(45)$ \\
\hline \multicolumn{2}{|l|}{ Molecular remission } \\
\hline Yes/no & $15(48) / 16(52)$ \\
\hline
\end{tabular}

${ }^{a)}$ Calculated by $\log$ (RQ-PCR value at time point/RQ-PCR value at baseline). ${ }^{\text {b) }} \mathrm{RQ}$-PCR value of ' 0. '

Abbreviations: $\mathrm{HCT}$, hematopoietic cell transplantation; RQ-PCR, real time quantitative polymerase chain reaction. 
molecular remission (RQ-PCR value of ' 0 ') post-consolidation and prior to HCT respectively.

Overall, 8 patients (26\%) showed an RQ-PCR value increase after transplant at a median time post-HCT of 9.2 months (range, 2.9-51.8 mo), requiring the initiation of imatinib with or without chemotherapy. Mean duration of subsequent TKI therapy was 7.4 months (range, 0.2-20.3). Three of the patients showed morphological relapses concurrent with the increase in the RQ-PCR value and received both imatinib and chemotherapy; two received a second HCT after achieving second CR and currently survive event-free, while the remaining patient showed a second relapse and died. Of the five patients who started imatinib for an RQ-PCR value increase without experiencing overt relapse, three achieved molecular remission and survived event-free; the remaining two patients, however, died from subsequent relapse and refractory disease, and veno-occlusive disease after second HCT, respectively.

\section{Survival outcomes}

With a median duration of 61.8 months follow-up for surviving patients, the 5-year EFS and OS of the study group were $64.5 \pm 9.4 \%[20 / 31$, relapse $(\mathrm{N}=5)$ and $\mathrm{NRM}(\mathrm{N}=6)]$ and $75.0 \pm 8.3 \%$ (23/31) (Fig. 1A, B). The 5-year incidence of relapse was $18.3 \pm 7.9 \%(5 / 31)$; sites of relapse in the 5 patients were $\mathrm{BM}(\mathrm{N}=3), \mathrm{BM}+\mathrm{CNS}(\mathrm{N}=1)$, and isolated testis $(\mathrm{N}=1)$. Three of these patients currently survive disease-free, including 2 who received second transplants. The 5-year incidence of molecular relapse was $30.9 \pm 9.1 \%$ (9/31); four of 9 patients showed increase in BM RQ-PCR only, without overt evidence of relapse. The 5-year incidence of NRM was $17.3 \pm 7.3 \%$; causes of NRM included chronic GVHD ( $\mathrm{N}=2)$, cerebral aspergillosis $(\mathrm{N}=1)$, thrombotic microangiopathy $(\mathrm{N}=1)$, veno-occlusive disease $(\mathrm{N}=1)$, and pulmonary hemorrhage $(\mathrm{N}=1)$.

\section{Prognostic factors}

None of the factors studied proved to significantly influ- ence EFS. Importantly, the steroid type utilized during chemotherapy and donor type for HCT did not affect EFS (5-year EFS $75.0 \pm 15.3 \%$ for matched related donor vs. $60.2 \pm 11.6 \%$ for unrelated donor; $P=0.443$ ) (Table 4). Patients who received a transplant from an HLA mismatched donor had

Table 4. Impact of risk factors for 5-year EFS and incidence of molecular relapse. ${ }^{\text {a }}$

\begin{tabular}{|c|c|c|c|c|c|}
\hline & Patients & EFS & $P$ & Relapse & $P$ \\
\hline Steroid type & & & 0.988 & & 0.584 \\
\hline Dexa & 12 & $66.7 \pm 13.6$ & & $25.0 \pm 13.2$ & \\
\hline Pred & 19 & $58.9 \pm 15.5$ & & $39.0 \pm 15.4$ & \\
\hline Donor type & & & 0.443 & & 0.587 \\
\hline $\begin{array}{r}\text { Matched } \\
\text { related }\end{array}$ & 8 & $75.0 \pm 15.3$ & & $37.5 \pm 18.7$ & \\
\hline Unrelated & 23 & $60.2 \pm 11.6$ & & $29.0 \pm 10.8$ & \\
\hline HLA & & & 0.100 & & 0.706 \\
\hline Match & 20 & $80.0 \pm 8.9$ & & $30.0 \pm 10.6$ & \\
\hline Mismatch & 11 & $39.8 \pm 16.3$ & & $31.8 \pm 17.5$ & \\
\hline $\begin{array}{l}\text { Additional } \\
\text { cytogenetics }{ }^{\text {b) }}\end{array}$ & & & 0.157 & & 0.329 \\
\hline Yes & 24 & $56.8 \pm 11.7$ & & $36.9 \pm 11.6$ & \\
\hline No & 7 & $85.7 \pm 13.2$ & & $14.3 \pm 14.3$ & \\
\hline $\begin{array}{l}\text { Post-Consol. } \geq \\
-4 \text { Log } \\
\text { reduction }^{\text {c) }}\end{array}$ & & & 0.409 & & 0.027 \\
\hline Yes & 13 & $76.9 \pm 11.7$ & & $7.7 \pm 7.7$ & \\
\hline No & 17 & $58.3 \pm 13.8$ & & $50.0 \pm 13.8$ & \\
\hline $\begin{array}{l}\text { Molecular } \\
\text { remission } \\
\text { before } \mathrm{HCT}^{\mathrm{d})}\end{array}$ & & & 0.130 & & 0.300 \\
\hline Yes & 15 & $53.3 \pm 12.9$ & & $20.0 \pm 10.8$ & \\
\hline No & 16 & $74.6 \pm 13.2$ & & $41.1 \pm 14.3$ & \\
\hline
\end{tabular}

${ }^{\text {a) }}$ Data for a subset of all risk factors analyzed. ${ }^{\text {b) }}$ Additional cytogenetic abnormalities besides Ph. ${ }^{\mathrm{c}}$ Based on RQ-PCR of the fusion transcript. ${ }^{\mathrm{d})} \mathrm{RQ}-\mathrm{PCR}$ value of ' 0. '

Abbreviations: Consol., Consolidation; Dexa, dexamethasone; $\mathrm{HCT}$, hematopoietic cell transplantation; HLA, human leukocyte antigen; Pred, prednisolone.
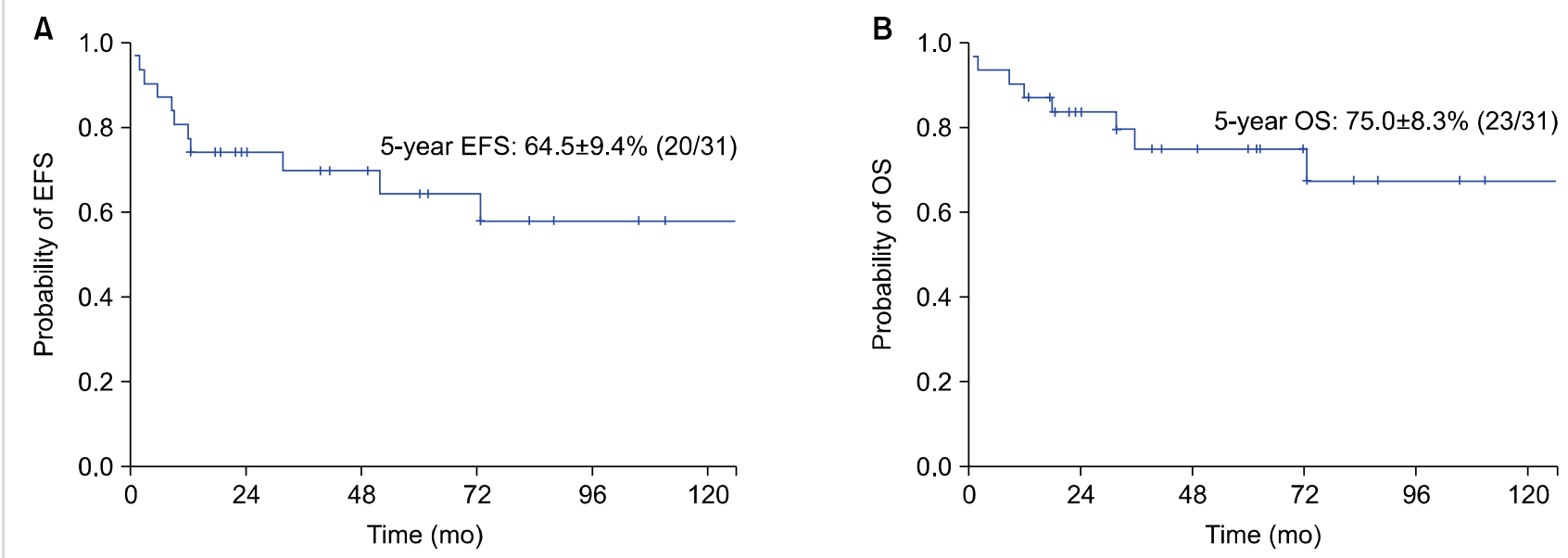

Fig. 1. Estimated 5-year EFS (A) and OS (B) of study patients. 
lower 5-year EFS, although the difference was not significant (HLA matched donor transplant $80.0 \pm 8.9 \%$ vs. HLA mismatched donor transplant $39.8 \pm 16.3 \% ; P=0.100)$. Also, patients who had additional cytogenetic abnormalities besides $\mathrm{Ph}$ had inferior 5-year EFS $(56.8 \pm 11.7 \%$ vs. $85.7 \pm 13.2 \%$ for those with $\mathrm{Ph}$ only; $P=0.157)$. Variables related to RQ-PCR value of the fusion transcript, such as extent of RQ-PCR decrements at any of the time points studied and the achievement of molecular remission prior to HCT, did not have a significant impact on EFS (Table 4).

Regarding the incidence of molecular relapse, MRD status after consolidation chemotherapy was the only significant factor, with those achieving $\geq-4 \log$ reduction of the BCR-ABL1 transcript having significantly lower incidences of molecular relapse compared to those with less reduction $(7.7 \pm 7.7 \%$ vs. $50.0 \pm 13.8 \% ; P=0.027)$ (Table 4$)$. Patients with additional cytogenetic abnormalities had higher incidences of molecular relapse compared to patients with $\mathrm{Ph}$ only (36.9 $\pm 11.6 \%$ vs. $14.3 \pm 14.3 \% ; P=0.329)$, although without statistical significance.

\section{DISCUSSION}

Here, we analyzed the outcome and risk factors for $\mathrm{Ph}+$ ALL who underwent a joint imatinib-chemotherapy treatment, with subsequent allogeneic HCT in first CR. Our 5-year EFS and OS rates of $64.5 \pm 9.4 \%$ and $75.0 \pm 8.3 \%$ were similar to those reported by recent studies on this ALL subtype [8, 12].

Favorable prognostic factors for children with $\mathrm{Ph}+\mathrm{ALL}$ treated in the pre-TKI era included clinical factors such as younger age, lower WBC count and favorable early BM response to remission induction chemotherapy $[13,14]$. However, variables which influence patient outcomes after treatments combining TKI and chemotherapy remain unclear, with limited previous studies on this issue. The most recent report of the COG AALL0031 trial showed that patients with additional cytogenetic abnormalities besides the $\mathrm{Ph}$ chromosome had lower EFS while the level of MRD post-induction, as detected by flow cytometry, had no impact on survival [8].

Although the analysis was undertaken on a small number of patients, we found that none of the factors studied had a clear impact on EFS, while the decrement of the fusion transcript measured by RQ-PCR post-consolidation was the only significant factor for incidence of molecular relapse post-transplant, with patients achieving at least a -4 Log decrease while having lower incidence of relapse. Molecular relapse was analyzed as an endpoint here because an increase in the fusion transcript RQ-PCR value post-HCT, though does not correspond with a clear, morphological relapse, translates into the re-initiation of TKI therapy with both TKI-related complication and future relapse risks. The significance of the post-consolidation RQ-PCR value found in our study is similar to the transcript level prognostic value that was detected after the first 4 weeks of imatinib therapy after remission induction, which was reported to be important in a study of adult Ph+ ALL patients [11].

Regarding other prognostic factors, we found that patients with additional cytogenetic abnormalities had lower EFS and greater incidence of relapse than those with the $\mathrm{Ph}$ chromosome only, although not to the significant extent found in the COG study [8]. Variables that did not affect EFS or incidence of relapse significantly were also meaningful. For example, as with the COG study, we found that end-induction MRD did not affect outcomes [8], and that RQ-PCR value prior to HCT, and whether the patient achieved molecular remission prior to HCT did not affect post-transplant outcome. Donor type did not influence EFS, supporting a previous study on the acceptable outcomes of alternative donor transplant for pediatric Ph+ ALL [15]. Importantly, however, patients who received transplant from an HLA mismatched donor had inferior EFS, possibly due to an increase in NRM.

A clear limitation of our retrospective study is the differing consolidation chemotherapy treatment undertaken in a minority of patients, resulting in a lack of uniformity regarding the post-consolidation time point at which the RQ-PCR study was undertaken. We also draw attention to the high incidence of chronic GVHD, especially the $32.4 \%$ incidence of at least moderate chronic GVHD among our patients. $\mathrm{Ph}+\mathrm{ALL}$ may be susceptible to a graft-versus-leukemia effect, lowering the risk of relapse [16]. However, the undertaking of allogeneic HCT for cure of Ph+ ALL may have resulted in long-term morbidity in a subset of our patients.

Further research is necessary to improve the outcome of this poor prognosis ALL subtype. TKI therapy may be started during remission induction, as exemplified in the Spanish Cooperative Group SHOP study in which imatinib was administered from day 15 of remission induction onwards [5]. One study found that the introduction of TKI at day 22 of induction produced a major decrease in MRD levels and improved EFS, underscoring the utility of early TKI initiation in decreasing leukemic burden [17]. Another modification that may improve EFS is the administration of TKI post-HCT as maintenance treatment, a regimen that resulted in a 73\% 5-year EFS in one pediatric study [18].

Second generation TKIs allow for better CNS penetration than imatinib. A recent study on dasatinib combined with chemotherapy for the treatment of Ph+ ALL showed survival outcomes similar to a cohort of patients treated with imatinib [19]. Importantly, this study showed that a subgroup of patients with IKZF1 deletion had significantly worse survival, emphasizing the role of this genetic mutation as a possible prognostic factor.

Finally, regarding methods to improve survival of $\mathrm{Ph}+$ ALL patients, reduced intensity conditioning for transplant may be considered. A report on a small series of patients showed that non-myeloablative conditioning may be a valid option, with four out of five patients surviving disease-free [20]. Validity of reduced intensity conditioning becomes important when one considers the 5-year incidence of NRM of $17 \%$ in our study. 
In summary, for our $\mathrm{Ph}+\mathrm{ALL}$ patients who started imatinib with chemotherapy post-induction and subsequently underwent allogeneic HCT in first CR, the magnitude of fusion transcript decrement during post-consolidation was the only significant factor for the incidence of molecular relapse after transplant. In the post-induction TKI initiation settings, steadfast treatment with imatinib during consolidation may allow for optimum post-HCT outcomes.

\section{Authors' Disclosures of Potential Conflicts of Interest}

No potential conflicts of interest relevant to this article were reported.

\section{REFERENCES}

1. Bleckmann K, Schrappe M. Advances in therapy for Philadelphiapositive acute lymphoblastic leukaemia of childhood and adolescence. Br J Haematol 2016;172:855-69.

2. Aricò M, Valsecchi MG, Camitta B, et al. Outcome of treatment in children with Philadelphia chromosome-positive acute lymphoblastic leukemia. N Engl J Med 2000;342:998-1006.

3. Aricò M, Schrappe M, Hunger SP, et al. Clinical outcome of children with newly diagnosed Philadelphia chromosome-positive acute lymphoblastic leukemia treated between 1995 and 2005. J Clin Oncol 2010;28:4755-61.

4. Schultz KR, Bowman WP, Aledo A, et al. Improved early event-free survival with imatinib in Philadelphia chromosomepositive acute lymphoblastic leukemia: a children's oncology group study. J Clin Oncol 2009;27:5175-81.

5. Rives S, Estella J, Gómez P, et al. Intermediate dose of imatinib in combination with chemotherapy followed by allogeneic stem cell transplantation improves early outcome in paediatric Philadelphia chromosome-positive acute lymphoblastic leukaemia (ALL): results of the Spanish Cooperative Group SHOP studies ALL-94, ALL-99 and ALL-2005. Br J Haematol 2011;154:600-11.

6. Biondi A, Schrappe M, De Lorenzo P, et al. Imatinib after induction for treatment of children and adolescents with Philadelphia-chromosome-positive acute lymphoblastic leukaemia (EsPhALL): a randomised, open-label, intergroup study. Lancet Oncol 2012;13:936-45.

7. Manabe A, Kawasaki $H$, Shimada $H$, et al. Imatinib use immediately before stem cell transplantation in children with Philadelphia chromosome-positive acute lymphoblastic leukemia: Results from Japanese Pediatric Leukemia/Lymphoma Study Group (JPLSG) Study Ph(+) ALL04. Cancer Med 2015;4:682-9.

8. Schultz KR, Carroll A, Heerema NA, et al. Long-term follow-up of imatinib in pediatric Philadelphia chromosome-positive acute lymphoblastic leukemia: Children's Oncology Group study AALL0031. Leukemia 2014;28:1467-71.

9. Lee JW, Kim SK, Jang PS, et al. Treatment of children with acute lymphoblastic leukemia with risk group based intensification and omission of cranial irradiation: a Korean study of 295 patients. Pediatr Blood Cancer 2016;63:1966-73.

10. Ottmann OG, Wassmann B, Pfeifer H, et al. Imatinib compared with chemotherapy as front-line treatment of elderly patients with Philadelphia chromosome-positive acute lymphoblastic leukemia (Ph+ALL). Cancer 2007;109:2068-76.

11. Lee S, Kim YJ, Chung NG, et al. The extent of minimal residual disease reduction after the first 4-week imatinib therapy determines outcome of allogeneic stem cell transplantation in adults with Philadelphia chromosome-positive acute lymphoblastic leukemia. Cancer 2009;115:561-70.

12. Zawitkowska J, Lejman M, Zaucha-Prażmo A, et al. Clinical characteristics and analysis of treatment result in children with $\mathrm{Ph}$-positive acute lymphoblastic leukaemia in Poland between 2005 and 2017. Eur J Haematol 2018;101:542-8.

13. Roy A, Bradburn M, Moorman AV, et al. Early response to induction is predictive of survival in childhood Philadelphia chromosome positive acute lymphoblastic leukaemia: results of the Medical Research Council ALL 97 trial. Br J Haematol 2005;129:35-44.

14. Gandemer V, Auclerc MF, Perel Y, et al. Impact of age, leukocyte count and day 21-bone marrow response to chemotherapy on the long-term outcome of children with philadelphia chromosomepositive acute lymphoblastic leukemia in the pre-imatinib era: results of the FRALLE 93 study. BMC Cancer 2009;9:14.

15. Talano JM, Casper JT, Camitta BM, et al. Alternative donor bone marrow transplant for children with Philadelphia chromosome ALL. Bone Marrow Transplant 2006;37:135-41.

16. Espérou H, Boiron JM, Cayuela JM, et al. A potential graft-versus-leukemia effect after allogeneic hematopoietic stem cell transplantation for patients with Philadelphia chromosomepositive acute lymphoblastic leukemia: results from the French Bone Marrow Transplantation Society. Bone Marrow Transplant 2003;31:909-18.

17. Jeha S, Coustan-Smith E, Pei D, et al. Impact of tyrosine kinase inhibitors on minimal residual disease and outcome in childhood Philadelphia chromosome-positive acute lymphoblastic leukemia. Cancer 2014;120:1514-9.

18. Byun YJ, Suh JK, Lee SW, et al. Favorable outcome of allogeneic hematopoietic stem cell transplantation followed by posttransplant treatment with imatinib in children with Philadelphia chromosome-positive acute lymphoblastic leukemia. Blood Res 2015;50:147-53.

19. Slayton WB, Schultz KR, Kairalla JA, et al. Dasatinib plus intensive chemotherapy in children, adolescents, and young adults with Philadelphia chromosome-positive acute lymphoblastic leukemia: results of Children's Oncology Group trial AALL0622. J Clin Oncol 2018;36:2306-14.

20. Yamada K, Yasui M, Kondo O, et al. Feasibility of reducedintensity allogeneic stem cell transplantation with imatinib in children with philadelphia chromosome-positive acute lymphoblastic leukemia. Pediatr Blood Cancer 2013;60:E60-2. 
Supplementary Table 1. Results of Giemsa band karyotyping of the bone marrow at diagnosis.

\begin{tabular}{|c|c|}
\hline UPN & Karyotype \\
\hline 1 & $46, \mathrm{XY}, \mathrm{t}(9 ; 22)(\mathrm{q} 34 ; \mathrm{q} 11.2)[1] / 45$, idem,--7[13]/46,XY[6] \\
\hline 2 & $46, X Y, t(9 ; 22)(q 34 ; q 11.2)[1] / 45$, idem,-7[18]/46,XY[1] \\
\hline 3 & $45, X X, \operatorname{der}(7 ; 9)(q 10 ; q 10) t(9 ; 22)(q 34 ; q 11.2), \operatorname{der}(22) t(9 ; 22)[9] / 46, X X[11]$ \\
\hline 4 & $46, X Y, t(9 ; 22)(q 34 ; q 11.2)[12] / 46, X Y[8]$ \\
\hline 5 & $46, X X, t(9 ; 22)(q 34 ; q 11.2)[16] / 46, X X[4]$ \\
\hline 6 & $61-70, X X Y<3 n>,-1, \operatorname{dup}(1)(q 12 q 42),+2,+4,+6,-7,-8,-9, t(9 ; 22)(q 34 ; q 11.2) \times 2[c p 18] / 46, X Y[2]$ \\
\hline 7 & $46, \mathrm{XY}, \mathrm{t}(9 ; 22)(\mathrm{q} 34 ; \mathrm{q} 11.2)[4] / 48$, idem $,+13,+17[16]$ \\
\hline 8 & $56, \mathrm{XY},+\mathrm{X},+\mathrm{Y},+2,+4,+6,+8, \mathrm{t}(9 ; 22)(\mathrm{q} 34 ; \mathrm{q} 11.2),+14,+18,+21,+\operatorname{der}(22) \mathrm{t}(9 ; 22)[20]$ \\
\hline 9 & $48, X Y, t(9 ; 22)(q 34 ; q 11.2),+21,+$ mar, inc $[1] / 46, X Y[19]$ \\
\hline 10 & $45, X X, \operatorname{del}(5)(q 33 q 35), \operatorname{der}(9) t(9 ; 22), \operatorname{der}(14 ; 22)(q 10 ; q 10) t(9 ; 22)(q 34 ; q 11.2)[15] / 45, X X, \operatorname{der}(14 ; 22)(q 10 ; q 10)[5]$ \\
\hline 11 & $46, \mathrm{XY}, \mathrm{t}(9 ; 22)(\mathrm{q} 34 ; \mathrm{q} 11.2)[6] / 46, \mathrm{XY}[14]$ \\
\hline 12 & $46, X Y, t(9 ; 22)(q 34 ; q 11.2), \operatorname{del}(19)(p 13.3)[15] / 46, s l, \operatorname{del}(7)(p 13)[4] / 46, X Y$ \\
\hline 13 & $46, X X, t(9 ; 22)(q 34 ; q 11.2)[3] / 49, X X,+X,+14,+21[1] / 46, X X[26]$ \\
\hline 14 & $46, X Y, 1 \mathrm{qh}+, \mathrm{t}(9 ; 22)(\mathrm{q} 34 ; \mathrm{q} 11.2)[4] / 45, \mathrm{XY}, 1 \mathrm{qh}+, \operatorname{der}(7 ; 9)(\mathrm{q} 10 ; \mathrm{q} 10) \mathrm{t}(9 ; 22)(\mathrm{q} 34 ; \mathrm{q} 11.2), \operatorname{der}(22) \mathrm{t}(9 ; 22)[2] / 46, \mathrm{XY}, 1 \mathrm{qh}+[24]$ \\
\hline 15 & $46, X Y, t(9 ; 22)(q 34 ; q 11.2)[20]$ \\
\hline 16 & $46, X Y, \operatorname{der}(9) \operatorname{del}(9)(\mathrm{p} 22) \mathrm{t}(9 ; 22)(\mathrm{q} 34 ; \mathrm{q} 11.2), \operatorname{der}(22) \mathrm{t}(9 ; 22)[7] 44, \operatorname{idem},-\mathrm{Y}, \mathrm{t}(8 ; 9)(\mathrm{p} 10 ; \mathrm{p} 10),-20[21] / 46, \mathrm{XY}[2]$ \\
\hline 17 & $46, x x$ \\
\hline 18 & $46, X Y, t(9 ; 22)(q 34 ; q 11.2), \operatorname{add}(14)(q 32)[16] / 46, X Y[4]$ \\
\hline 19 & $46, X Y, t(9 ; 22)(q 34 ; q 11.2)[24] / 46, X Y[6]$ \\
\hline 20 & $46, X Y, t(9 ; 22)(q 34 ; q 11.2)[37] / 61-62$, idem $,+X,+1,+1,+2,+12,+17,+18,+19,+21,+\operatorname{der}(22) t(9 ; 22),+\operatorname{mar}[\mathrm{cp} 2] / 46, X Y[1]$ \\
\hline 21 & $46, X X, t(2 ; 12)(p 13 ; p 13), t(9 ; 22)(q 34 ; q 11.2)[17] / 46, X X[3]$ \\
\hline 22 & $46, X Y, t(9 ; 22 ; ? 1)(q 34 ; q 11.2 ; ? p 36.1)[1] / 45$, idem, der(7;12)(q10;q10)[10]/46,XY[19] \\
\hline 23 & $47, \mathrm{XX}, \mathrm{t}(9 ; 22)(\mathrm{q} 34 ; \mathrm{q} 11.2),+10[20]$ \\
\hline 24 & $46, X X, \operatorname{ider}(9)(q 10) t(9 ; 22)(q 34 ; q 11.2), \operatorname{ider}(22)(q 10) t(9 ; 22)[2] / 47, i d e m,+\operatorname{ider}(22)(q 10) t(9 ; 22)[27] / 46, X X[1]$ \\
\hline 25 & $46, \mathrm{XX}, \mathrm{t}(9 ; 22)(\mathrm{q} 34 ; \mathrm{q} 11.2)[1] / 53, \mathrm{idem},+5,+6,+8,+10,+12,+13,+15[\mathrm{cp} 11] / 46, \mathrm{XX}[8]$ \\
\hline 26 & $45, \mathrm{XY}, \mathrm{t}(9 ; 22)(\mathrm{q} 34 ; \mathrm{q} 11.2),-20[19] / 46, \mathrm{XY}[1]$. nuc ish $(\mathrm{p} 16 \times 1),(\mathrm{CEP} 9 \times 2)[370 / 400]$ \\
\hline 27 & $\begin{array}{l}\text { 46,XY,der(9)t(9;17)(p13;p11.2)t(9;22)(q34;q11.2), der(17)t(9;17), der(22)t(9;22)[20]/45,XY,t(8;14)(p23;q24),t(9;22), der(11;20)(p10;p10)[6 } \\
\text { ]/46,sdl1,+mar[2]/46,XY[2] }\end{array}$ \\
\hline 28 & $46, X X, t(9: 22)(q 34 ; q 11.2)[20]$ \\
\hline 29 & $46, X Y, t(9 ; 22)(q 34 ; q 11.2)[7] / 46, \operatorname{idem}, \operatorname{del}(9)(p 21)[9] / 53, i d e m,+2,+5,+7,+10,+11,+21,+\operatorname{der}(22) t(9 ; 22)[1] / 46, X Y[3]$ \\
\hline 30 & $47, \mathrm{XY},+\operatorname{add}(1)(\mathrm{p} 13), \mathrm{t}(9 ; 22)(\mathrm{q} 34 ; \mathrm{q} 11.2)[20]$ \\
\hline 31 & $46, X Y, \operatorname{der}(5) t(1 ; 5)(q 12 ; q 15), t(9 ; 22)(q 34 ; q 11.2)[12] / 46, X Y[8]$ \\
\hline
\end{tabular}

Supplementary Table 2. Remission induction and consolidation for CMCP-ALL.

\begin{tabular}{|c|c|c|}
\hline Drug & Dose & Days \\
\hline \multicolumn{3}{|l|}{ Prephase (1 wk) } \\
\hline Prednisolone $(\mathrm{PO})^{\mathrm{a})}$ & $60 \mathrm{mg} / \mathrm{m}^{2}$ (max. $80 \mathrm{mg}$ ) & $1-7$ \\
\hline Methotrexate/cytarabine/hydrocortisone (IT) & By age $^{\text {b) }}$ & 1 \\
\hline \multicolumn{3}{|l|}{ Remission induction $(4 \mathrm{wk})$} \\
\hline Vincristine (IV) & $1.5 \mathrm{mg} / \mathrm{m}^{2}$ (max. $2 \mathrm{mg}$ ) & $1,8,15,22$ \\
\hline Daunorubicin (IV) & $45 \mathrm{mg} / \mathrm{m}^{2}$ & 1 \\
\hline I-asparaginase (IM) & $6,000 \mu / \mathrm{m}^{2}(\max .10,000 \mu)$ & $2,4,6,9,11,13,16,18,20$ \\
\hline Prednisolone (PO) & $60 \mathrm{mg} / \mathrm{m}^{2}(\max .80 \mathrm{mg})$ & $1-21$ \\
\hline Methotrexate (IT) & By age $^{c)}$ & 1,22 \\
\hline \multicolumn{3}{|l|}{ Consolidation $(8 \mathrm{wk})$} \\
\hline Cyclophosphamide (IV) & $1,000 \mathrm{mg} / \mathrm{m}^{2}$ & 1,29 \\
\hline Cytarabine (IV) & $100 \mathrm{mg} / \mathrm{m}^{2}$ & $1-5,15-19,29-33,43-47$ \\
\hline Vincristine (IV) & $1.5 \mathrm{mg} / \mathrm{m}^{2}(\max .2 \mathrm{mg})$ & $15,22,43,50$ \\
\hline Prednisolone (PO) & $45 \mathrm{mg} / \mathrm{m}^{2}(\max .60 \mathrm{mg})$ & $22-26,50-54$ \\
\hline 6 -Mercaptopurine (PO) & $60 \mathrm{mg} / \mathrm{m}^{2}$ & $1-7,29-35$ \\
\hline Methotrexate (IT) & By age ${ }^{c)}$ & $1,15,29,43$ \\
\hline
\end{tabular}

a) For patients diagnosed and treated from January 2009 onwards, prednisolone was used for treatment. However, for patients diagnosed from January 2005 to December 2008, dexamethasone was used at a dose of $8 \mathrm{mg} / \mathrm{m}^{2} /$ day PO (max. $10 \mathrm{mg} /$ day) during all phases of steroid treatment from prephase to end of maintenance treatment. ${ }^{\mathrm{b})} \mathrm{Age}$-adjusted doses of triple intrathecal chemotherapy: Methotrexate $6 \mathrm{mg}(<1 \mathrm{yr}), 7.5 \mathrm{mg}(\geq 1 \mathrm{and}<2 \mathrm{yr}), 10 \mathrm{mg}$ ( $\geq 2$ and $<3 \mathrm{yr}), 12.5 \mathrm{mg}(\geq 3 \mathrm{yr}) ;$ cytarabine $12 \mathrm{mg}(<1 \mathrm{yr}), 15 \mathrm{mg}$ ( $\geq 1$ and $<2 \mathrm{yr}), 20 \mathrm{mg}$ ( $\geq 2$ and $<3 \mathrm{yr}), 25 \mathrm{mg}$ ( $\geq 3 \mathrm{yr}) ;$ hydrocortisone $12 \mathrm{mg}$ $(<1 \mathrm{yr}), 15 \mathrm{mg}$ ( $\geq 1$ and $<2 \mathrm{yr}), 20 \mathrm{mg}(\geq 2$ and $<3 \mathrm{yr}), 25 \mathrm{mg}(\geq 3 \mathrm{yr}) .{ }^{\mathrm{c}}$ Age-adjusted doses of intrathecal methotrexate: $6 \mathrm{mg}(<1 \mathrm{yr}), 7.5 \mathrm{mg}(\geq 1$ and $<2 \mathrm{yr}), 10 \mathrm{mg}(\geq 2$ and $<3 \mathrm{yr}), 12.5 \mathrm{mg}(\geq 3 \mathrm{yr})$.

Abbreviations: IM, intramuscular; IT, intrathecal; IV, intravenous; PO, per os. 